\title{
Optimization and functionality of millet supplemented pasta
}

\author{
Amir GULL ${ }^{1}$, Kamlesh PRASAD ${ }^{1}$, Pradyuman KUMAR ${ }^{1 *}$
}

\begin{abstract}
Millets are having superior nutritional qualities and health benefits; hence they can be used for supplementation of pasta. Pasta was prepared using composite flour (CF) of durum wheat semolina (96\%) and carrot pomace (4\%) supplemented with finger millet flour (FMF, 0-20g), pearl millet flour (PMF, 0-30g) and carboxy methyl cellulose (CMC, 2-4g). Second order polynomial described the effect of FMF, PMF and CMC on lightness, firmness, gruel loss and overall acceptability of extruded pasta products. Results indicate that an increasing proportion of finger and pearl millet flour had signed $(\mathrm{p} \leq 0.05)$ negative effect on lightness, firmness, gruel loss and overall acceptability. However, CMC addition showed significant $(\mathrm{p} \leq 0.05)$ positive effect on firmness, overall acceptability and negative effect on gruel loss of cooked pasta samples. Numeric optimization results showed that optimum values for extruded pasta were 20g FMF, $12 \mathrm{~g}$ PMF and $4 \mathrm{~g}$ CMC per $100 \mathrm{~g}$ of CF and $34 \mathrm{ml}$ water with 0.981 desirability. The pasta developed is nutritionally rich as it contains protein $(10.16 \mathrm{~g})$, fat $(6 \mathrm{~g})$, dietary fiber $(16.71 \mathrm{~g})$, calcium $(4.23 \mathrm{mg})$, iron $(3.99 \mathrm{mg})$ and zinc $(1.682 \mathrm{mg})$ per $100 \mathrm{~g}$.
\end{abstract}

Keywords: finger millet; pearl millet; pasta; firmness; gruel loss; carboxy methyl cellulose.

Practical Application: Millets are highly nutritious, rich in health promoting phytochemicals and dietary fiber. The aim of this work was to optimize the proportion of millet flours and carrot pomace for development of functional pasta. The present study showed that pasta with good nutritional and functional properties can be obtained from blends of millet flours and carrot pomace. Moreover the results of this study could provide useful information about potential utilization of millet grains in food formulations and product development for new functional foods.

\section{Introduction}

Dried pasta represents a basic food for populations living in several countries of Southern Europe, particularly in Italy. The concept of pasta quality for Italian consumers comes from their traditional habits and it is strictly dependent on the usage of durum wheat (Triticum durum) as raw material (Noni \& Pagani, 2010). Pasta being stable food product is produced mainly by mixing durum semolina and water. Although more recently other grains have been used to partially replace durum semolina (Chillo et al., 2008). In addition, pseudo cereals have also been used to prepare gluten free (GF) or low glycemic index pastas for special nutrition (Caperuto et al., 2001; Alamprese et al., 2007). However, some people with a specific genetic nature suffer from celiac disease which is usually manifested as a digestive malfunction of the intestines caused by the presence of gluten. This diet excludes intake of storage proteins found in wheat, rye, barley, and oats (Yalcin \& Basman, 2008; Schoenlechner et al., 2010; Juszczak et al., 2012). As millets are gluten free thus these are appropriate food for those with celiac disease or other forms of allergies or wheat intolerance (Saravana \& Soam, 2010). This information indicates the need for new gluten reduced or gluten-free products in the market such as pasta.

Functional properties determine the quality characteristics of pasta including firmness, gruel loss and overall acceptability. High quality pasta has a good cooking resistance and firmness, does not release an excessive amount of organic matter into the cooking water and does not show stickiness. Moreover the pasta quality is related to a low breakage susceptibility to dry conditions. Many studies have been carried out to develop functional pasta viz, cereal brans enriched pasta (Kaur et al., 2012), fresh rice pasta (Fernandes et al., 2013).

Finger millet (Eleusine coracana) also known as ragi is one of the important millet consumed without dehulling. It has a well-balanced amino-acid profile and is good source of methionine, cysteine and lysine. It also contains $72 \%$ carbohydrates major proportion of which is in the form of non-starchy polysaccharides and dietary fiber, which upon consumption helps in constipation and lowering of glucose level in blood. It is a rich source of vitamins viz, thiamine, riboflavin, folic acid, and niacin (Vidyavati et al., 2004).

Pearl millet (Pennisetum typhoids) is an important coarse cereal grain. Nutritive value of pearl millet is equivalent or even superior to other cereals (Obilana \& Manyasa, 2002). It has high levels of calcium, iron, zinc, lipids and a well- balance protein with high concentrations of threonine and tryptophan along with less (but adequate) leucine than other cereals.

Carrot is one of the important root vegetable rich in bioactive compounds like carotenoids and dietary fibers with appreciable levels of several other functional components having significant health promoting properties (Sharma et al., 2012). 
Carrot juice yield reported to be only $60-70 \%$ and one third of the raw material remain as pomace which is mainly disposed as feed which contains large amounts of valuable components such as carotenes and dietary fiber. Carrot consumption has been shown to positively influence antioxidant status in healthy human subjects (Bub et al., 2000).

Generally gums and thickeners such as (carboxy methyl cellulose and guar gum) aid in gelling, thickening, water retention and texture improvement (Gallagher et al., 2004) can be utilized for the development of healthy pasta products. The nutritional value of pasta is not very high as it is rich in starch and devoid of dietary fiber. Incorporation of high fiber material enhances the nutritional and functional quality of pasta (Sudha \& Leelavathi, 2012). Keeping in view of the above findings of researchers, finger and pearl millet flour incorporated with carrot pomace was used to develop the pasta. The use of hydrocolloid may yield acceptable pasta with good texture and minimum cooking loss.

Therefore the present study was aimed to optimize the pasta formulations of high nutritive value comprising finger millet flour (FMF), pearl millet flour (PMF) and carboxy methyl cellulose (CMC).

\section{Materials and methods}

Durum wheat semolina was procured from Goyal Wheat Milling Industries, Indore (India). Finger millet and Pearl millet (HHB-67) were obtained Shimla and Hisar (India). Millet flours and carrot pomace was prepared as per method used by (Gull et al., 2015). Carboxy methyl cellulose was procured from Loba Chemie Pvt. Ltd (Mumbai). All the chemicals used for analysis were of analytical grade.

\subsection{Experimental design}

Second order polynomial (SOP) model was used to describe the effect of finger millet flour (FMF), pearl millet flour (PMF) and carboxymethyl cellulose (CMC) for the development of nutrient rich and functional pasta. Each independent variable was used according to preliminary trials. Central composite rotatable design (CCRD) was selected for conduct of 30 runs by varying finger millet flour 0-20g, pearl millet flour 0-30g, CMC $2-4 \mathrm{~g} 100 \mathrm{~g}^{-1}$ of composite flour (CF) (containing durum wheat semolina and carrot pomace in ratio of $96: 4$ ) and water $31-35 \mathrm{ml}$ $100 \mathrm{~g}^{-1}$ of ingredient premix. Levels of these variables along with the experimental plan are shown Table 1. The proportion of FMF, PMF and CMC was optimized with a target for the development of nutrient rich and functional pasta.

\subsection{Preparation of pasta}

Weighed amount of composite flour and other supplemented ingredients (Table 1, run 1-30) were put into pasta mixer-extruder. Measured amount of water (Table1) was slowly added mixed and kneaded into stiff plastic and homogenous dough. The dough was then passed through a single screw extruder (Model: Dolly La Monferrina Italy) fitted with an adjustable die (diameter $7 \mathrm{~mm}$ ). The extruded product tube type pasta (Ziti-Cut) was cut into pieces of uniform length $(2.54 \mathrm{~cm})$ with a knife moving over the outer die surface. The extruded pasta was dried at $60^{\circ} \mathrm{C}$ for about 3- $4 \mathrm{~h}$ to attain moisture content to about $9 \%(\mathrm{db})$.
The resultant dried pasta products of various blends were packed in high density polyethylene (HDPE) bags kept in refrigerator for further analysis.

\subsection{Cooking characteristics of pasta}

Optimal Cooking Time (OCT)

The optimal cooking time (OCT) was evaluated every $30 \mathrm{~s}$ during cooking by observing the time of disappearance of the core of pasta by squeezing between two transparent glass slides according to the AACC approved method 66-50 (American Association of Cereal Chemists, 2000).The time at which the core completely disappeared was taken as the OCT using method (AACC 16-50).

\section{Color evaluation}

Color of the cooked pasta samples was determined using a colorimeter (Model CR-10, Konica Minolta Sensing, Inc. Japan) equipped with D65 illuminant. Measurements were made at random locations on the surface of the cooked pasta and lightness $\left(\mathrm{L}^{*}\right)$ values were noted. Three measurements were taken for each sample and their average value was reported.

\section{Gruel loss}

Ten grams of the sample were cooked in pan containing $300 \mathrm{ml}$ of boiling water for optimum cooking time. The cooking water was drained into beaker and $25 \mathrm{ml}$ of the cooking water was pipetted out and evaporated to dryness in hot air oven at $105^{\circ} \mathrm{C}$ to determine the solids loss in the gruel and expressed as $\%$ gruel loss using method (AACC 16-50). Three measurements were taken for each sample and their average value was reported (American Association of Cereal Chemists, 2000).

\section{Texture analysis}

The firmness was measured as described by Prabhasankar et al. (2009) with slight modification. The firmness of cooked pasta samples was measured by using a texture analyzer model (TA-XT2., Stable Micro systems, UK). Three-cooked pasta samples were sheared at a $90^{\circ}$ angle. The shear was performed at a crosshead speed of $10 \mathrm{~mm} / \mathrm{min}$ and load cell of $5 \mathrm{~kg}$. The force required to shear the pasta was measured. The results reported are the averaged of three readings.

\section{Overall acceptability}

Sensory analysis of cooked pasta was carried out using nine point hedonic scale (Ranganna, 1986) by a semi-trained panel of 15 members. The panel evaluated the pasta for sensory parameters like color, appearance, texture and taste and mean value of the score was considered as overall acceptability.

\subsection{Statistical analysis}

Statistical analysis was conducted using a statistical package, Design-Expert version 6.0.10 (Stat-Ease Inc., Minneapolis, USA). Statistical significance of the terms was examined by analysis of variance (ANOVA) for each response. 
Table 1. Effect of independent variables on functional qualities of pasta.

\begin{tabular}{|c|c|c|c|c|c|c|c|c|}
\hline $\begin{array}{l}\text { Run } \\
\text { No. }\end{array}$ & $\begin{array}{c}\text { FMF } \\
\left(\mathrm{g} .100 \mathrm{~g}^{-1} \mathrm{CF}\right)\end{array}$ & $\begin{array}{c}\text { PMF (g.100g }{ }^{-1} \\
\text { CF) }\end{array}$ & $\begin{array}{c}\text { CMC } \\
\left.\text { (g.100g- }{ }^{-1} \mathrm{CF}\right)\end{array}$ & $\begin{array}{c}\text { Water } \\
\left(\mathrm{mL} .100 \mathrm{~g}^{-1}\right. \\
\text { ingredient premix })\end{array}$ & $\begin{array}{c}\text { Lightness } \\
\mathrm{L}^{*}\end{array}$ & Firmness $(\mathrm{N})$ & $\begin{array}{c}\text { Gruel loss } \\
(\%)\end{array}$ & OAA \\
\hline 1 & 10 & 15 & 2 & 33 & 59.83 & 1.51 & 7.60 & 6.40 \\
\hline 2 & 15 & 7.5 & 2.5 & 34 & 54.75 & 2.08 & 7.10 & 6.40 \\
\hline 3 & 5 & 7.5 & 2.5 & 32 & 57.40 & 2.98 & 6.60 & 6.80 \\
\hline 4 & 5 & 7.5 & 3.5 & 34 & 57.40 & 3.70 & 5.80 & 7.90 \\
\hline 5 & 15 & 22.5 & 2.5 & 32 & 54.58 & 1.50 & 8.12 & 7.20 \\
\hline 6 & 10 & 15 & 3 & 33 & 54.02 & 2.40 & 6.50 & 7.10 \\
\hline 7 & 5 & 22.5 & 3.5 & 32 & 53.60 & 2.65 & 6.63 & 8.10 \\
\hline 8 & 15 & 22.5 & 3.5 & 34 & 53.30 & 2.85 & 7.58 & 7.50 \\
\hline 9 & 10 & 15 & 4 & 33 & 58.50 & 3.29 & 5.30 & 7.40 \\
\hline 10 & 5 & 22.5 & 2.5 & 34 & 54.10 & 2.39 & 6.96 & 6.20 \\
\hline 11 & 5 & 7.5 & 2.5 & 34 & 57.00 & 3.13 & 6.21 & 6.30 \\
\hline 12 & 15 & 22.5 & 3.5 & 32 & 54.45 & 2.81 & 7.60 & 7.00 \\
\hline 13 & 10 & 30 & 3 & 33 & 50.10 & 1.73 & 8.12 & 7.50 \\
\hline 14 & 20 & 15 & 3 & 33 & 52.33 & 2.30 & 7.10 & 6.30 \\
\hline 15 & 10 & 15 & 3 & 33 & 54.19 & 2.43 & 6.58 & 6.90 \\
\hline 16 & 10 & 15 & 3 & 33 & 53.10 & 2.70 & 6.90 & 7.00 \\
\hline 17 & 10 & 15 & 3 & 33 & 54.00 & 2.51 & 6.39 & 7.00 \\
\hline 18 & 10 & 15 & 3 & 31 & 52.40 & 2.50 & 6.43 & 7.00 \\
\hline 19 & 10 & 15 & 3 & 35 & 52.00 & 2.45 & 6.52 & 7.00 \\
\hline 20 & 15 & 7.5 & 2.5 & 32 & 54.98 & 2.12 & 7.02 & 6.10 \\
\hline 21 & 15 & 7.5 & 3.5 & 32 & 55.10 & 3.18 & 5.03 & 6.50 \\
\hline 22 & 0 & 15 & 3 & 33 & 56.10 & 3.26 & 6.35 & 7.30 \\
\hline 23 & 10 & 15 & 3 & 33 & 53.00 & 2.38 & 6.48 & 6.50 \\
\hline 24 & 10 & 0 & 3 & 33 & 55.10 & 3.22 & 5.10 & 6.80 \\
\hline 25 & 5 & 22.5 & 2.5 & 32 & 54.40 & 2.01 & 6.94 & 7.30 \\
\hline 26 & 10 & 15 & 3 & 33 & 54.15 & 2.53 & 6.28 & 6.90 \\
\hline 27 & 5 & 7.5 & 3.5 & 32 & 58.00 & 3.11 & 6.12 & 7.50 \\
\hline 28 & 15 & 7.5 & 3.5 & 34 & 54.80 & 3.09 & 5.13 & 7.50 \\
\hline 29 & 5 & 22.5 & 3.5 & 34 & 52.70 & 3.02 & 6.60 & 7.40 \\
\hline 30 & 15 & 22.5 & 2.5 & 34 & 56.90 & 1.45 & 8.40 & 6.70 \\
\hline
\end{tabular}

FMF (finger millet flour), PMF (pearl millet flour) CMC (carboxy methyl cellulose), CF (composite flour, durum wheat semolina: carrot pomace: 96:4) OAA (overall acceptability).

\section{Results and discussion}

Diagnostic checking of the second order polynomial fitted models for all responses are given in Table 2. The linear, quadratic and interaction effects were calculated for each model. The regression coefficients and correlation coefficients for each model are shown in Table 3. The model was considered adequate when the multiple coefficients of correlation $\left(R^{2}\right)$ were more than $93 \%$ and the lack of fit test was non-significant. The $\left(R^{2}\right)$ values for the responses i.e. lightness, firmness, gruel loss and overall acceptability were $0.93,0.97,0.95$, and 0.93 . The calculated F-values were more than the tabulated value for the responses indicating adequacy of the models at 5\% level of significance. Thus all four responses were considered adequate to describe the effect of variables on the quality of pasta.

\subsection{Color}

Color plays a major role in consumer's perception and acceptability of the product. The observed color $\left(\mathrm{L}^{\star}\right)$ value of cooked pasta with different combinations of the ingredients varied from 50.10 to 59.83 as shown in Table 1 . Figure 1 a represents change in lightness $\left(L^{*}\right)$ value of pasta with addition of finger and pearl millet flours, both millet flours significantly $(p \leq 0.05)$ decreased the lightness $\left(L^{*}\right)$ value of prepared pasta samples at linear level. This may be due to the brick red color of finger millet seed coat and grey color of pearl millet flour (Gull et al., 2015). Rathi et al. (2004) also observed that $L^{\star}$ value of pasta prepared from native pearl millet was lower than the pasta prepared from depigmented pearl millet flour. This difference in color of millet flours is due to the polyphenolic pigments present in pericarp, aleuronic layer and in endosperm region (McDonough \& Rooney, 1989).

\subsection{Texture}

Texture has been defined as one of the important attribute of pasta structure and textural characteristics are recognized as more important for consumers (Brennan \& Tudorica, 2007). The observed firmness values for different combinations varied from $1.45 \mathrm{~N}$ to $3.29 \mathrm{~N}$ as shown in Table 1 . Regression coefficient Table 3 showed that firmness of pasta samples is significantly 
Table 2. Analysis of variance for different models.

\begin{tabular}{|c|c|c|c|c|c|}
\hline Response & Source of variation & $\mathrm{df}$ & Sum of squares & Mean square & F-value \\
\hline \multirow[t]{3}{*}{ Lightness } & Model & 14 & 124.3 & 8.88 & $15.99^{*}$ \\
\hline & Residual & 15 & 8.33 & 0.56 & \\
\hline & Cor.Total & 29 & 132.6 & - & \\
\hline \multirow[t]{3}{*}{ Firmness } & Model & 14 & 9.43 & 0.67 & $41.42^{\star}$ \\
\hline & Residual & 15 & 0.24 & 0.01 & \\
\hline & Cor.Total & 29 & 9.67 & - & \\
\hline \multirow[t]{3}{*}{ Gruel Loss } & Model & 10 & 20.3 & 2.03 & $30.49^{*}$ \\
\hline & Residual & 19 & 1.27 & 0.06 & \\
\hline & Cor.Total & 29 & 21.6 & - & \\
\hline \multirow[t]{3}{*}{ OAA } & Model & 14 & 6.90 & 0.49 & $14.87^{\star}$ \\
\hline & Residual & 15 & 0.50 & 0.03 & \\
\hline & Cor.Total & 29 & 7.40 & - & \\
\hline
\end{tabular}

${ }^{\star}$ Significant at $\mathrm{p}<0.05$.

Table 3. Estimated coefficients of the best fitted SOP equation for different response of pasta.

\begin{tabular}{|c|c|c|c|c|}
\hline \multicolumn{5}{|c|}{ Estimated coefficients } \\
\hline Factor & Lightness & Firmness & Gruel loss & OAA \\
\hline$\beta 0$ & $53.74^{\star *}$ & $2.49^{\star *}$ & $6.52^{\star *}$ & $6.90^{\star *}$ \\
\hline$\left(\beta_{1}\right)$ & $-1.11^{*}$ & $-0.48^{* *}$ & $0.46^{*}$ & $-0.38^{*}$ \\
\hline$\left(\beta_{3}\right)$ & - & $0.86^{\star *}$ & $-0.95^{\star *}$ & $0.70^{\star *}$ \\
\hline$\left(\beta_{4}\right)$ & - & - & - & - \\
\hline$\left(\beta_{3}^{2}\right)$ & $5.87^{\star *}$ & - & - & - \\
\hline$\left(\beta_{4}^{2}\right)$ & - & - & - & - \\
\hline$\left(\beta_{1} \beta_{2}\right)$ & $3.65^{\star}$ & - & $1.25^{*}$ & - \\
\hline$\left(\beta_{1} \beta_{3}\right)$ & - & $0.70^{\star *}$ & $-0.93^{\star}$ & $-0.55^{\star}$ \\
\hline$\left(\beta_{1} \beta_{4}\right)$ & - & $-0.40^{*}$ & - & $0.80^{\star}$ \\
\hline Lack of fit & $0.1819(\mathrm{NS})$ & $0.4279(\mathrm{NS})$ & $0.2613(\mathrm{NS})$ & $0.7501(\mathrm{NS})$ \\
\hline
\end{tabular}

${ }^{\star}$ Significant at $\mathrm{p}<0.05 .{ }^{*}$ Significant at $\mathrm{p}<0.0001$. NS - Non-Significant.

affected $(\mathrm{p} \leq 0.05)$ by the $\mathrm{CMC}$ at linear level. This may be due to the hydrophilic component of hydrocolloids interacts with proteins as a result of ionic charges and thereby improving the structure of pasta (Raina et al., 2005). Yadav et al. (2014) also reported increase in firmness of non-wheat pasta based with CMC. Figure $1 b, c$ shows that both finger and pearl millet flour caused significant decrease $(\mathrm{p} \leq 0.05)$ in firmness value at linear level. It is due to the dilution of gluten strength by addition of non gluten containing millet flours and carrot pomace which interrupts and weakens the overall structure of pasta thus reducing firmness. Similarly (Krishnan \& Prabhasankar, 2010) reported the same results in durum wheat pasta incorporated with sprouted finger millet and green banana flours.

\subsection{Gruel loss}

The amount of residue in the cooking water is commonly used as an indicator of pasta quality. Low amount of residue indicates high quality pasta. For high quality pasta, the residue should not exceed $7-8 \%$ of the dry weight of pasta. The observed gruel loss of different combinations of pasta varied from 5.03 to 8.12 Table 1. As shown in Figure 1d gruel loss of cooked pasta decreased significantly $(\mathrm{p} \leq 0.05)$ with increase in CMC level. This could be due to the fact that gum network formation occurred around starch granules which encapsulate them during cooking and restricting the excessive swelling and diffusion of amylose content. Chillo et al. (2007) also observed decrease in gruel loss in spaghetti due to the addition of CMC. Shiau (2004) reported the similar reports that reduction in gruel loss in pasta containing gums. Figure $1 \mathrm{~d}$, e shows that both millet flours cause significant increase $(\mathrm{p} \leq 0.05)$ in gruel loss at linear level. This could be due to the reason, as millets are gluten free and addition of these dilutes gluten results in poor protein network and thus allow more leaching out of solids from pasta into the cooking water, hence increased the gruel loss. 

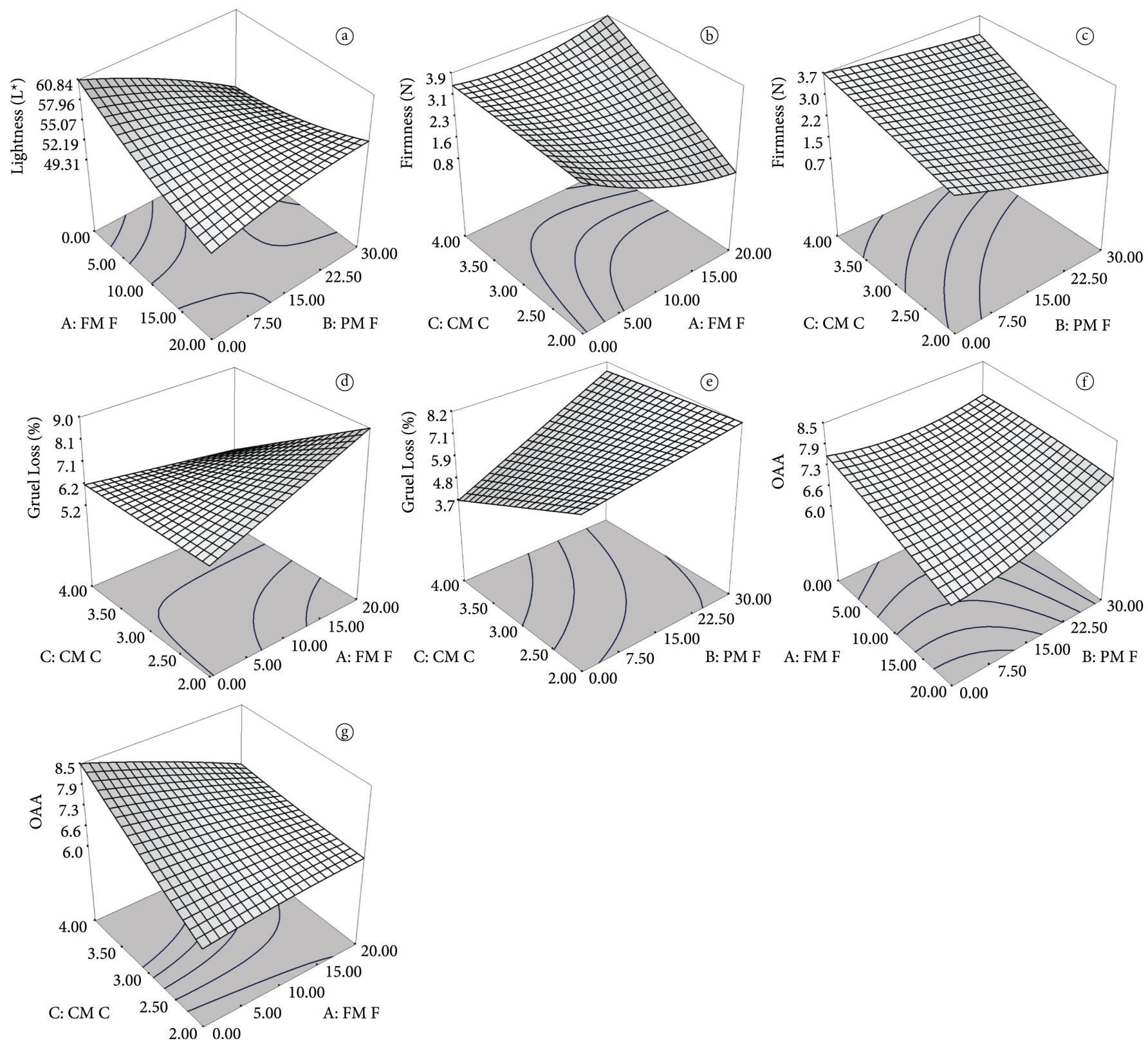

Figure 1. Response surface plot for cooking test parameters of fresh pasta (a) Lightness; (b, c) Firmness (N); (d, e) Gruel loss (\%); (f, g) Overall acceptability.

\subsection{Overall acceptability}

Sensory evaluation is most reliable test as it allows overall characteristics of cooked pasta. Effect of various process parameters on overall acceptability (OAA) is indicated in Figure 1f, g. The overall acceptability of cooked pasta with in the combinations varied from 6.2 to 8.1 Table 1. As shown in Figure $1 \mathrm{fOAA}$ decreased by increasing the proportion of finger and pearl millet flours. This may be due to unattractive dark color of finger millet and grey to yellow color of pearl millet which limits the wider acceptability of its food products. As shown in Figure $1 \mathrm{~g}$ addition of CMC increased OAA of cooked pasta. This could be attributed due to improvement in texture. Similarly Yadav et al. (2014) also observed increase in OAA with CMC for non-wheat pasta based on pearl millet flour containing barley and whey protein concentrate.

\section{Optimization}

A numerical multi-response optimization technique of RSM was applied to determine the optimum combination of FMF, PMF and CMC for the production of nutrient rich and functional pasta. The main criteria of optimization were maximum for lightness, firmness, overall acceptability and minimum for gruel loss as shown in Table 4. From the numerical response analysis it was found that optimum values were $20 \mathrm{~g}$ FMF, $12 \mathrm{~g}$

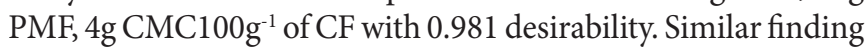
are reported by Yadav et al. (2014) for CMC addition in nonwheat pasta based on pearl millet flour containing barley and 
Table 4. Constraints, criteria for optimization solution along with predicted and actual response values.

\begin{tabular}{lcccc}
\hline \multicolumn{1}{c}{ Constraints } & Goal & Lower Limit & Upper limit & Predicted Values \\
\hline Finger millet flour g.100g ${ }^{-1} \mathrm{DWS}$ & Target & 0 & 20 & 20 \\
Pearl millet flour g.100 g ${ }^{-1} \mathrm{DWS}$ & Target & 0 & 30 & 12 \\
CMC g. 100 $\mathrm{g}^{-1} \mathrm{DWS}$ & In range & 2 & 4 & 4 \\
Water, ml. $100 \mathrm{~g}^{-1}$ ingredient premix & In range & 31 & 35 & 34.71 \\
Lightness L & Target & 53.09 & 54.39 & 53.74 \\
Firmness, N & Maximum & 2.38 & 6.60 & 2.5 \\
Gruel loss, $\%$ & Minimum & 6.55 & 6.75 & 6.6 \\
OAA & Maximum & 6.74 & 7.06 & 6.9 \\
\hline
\end{tabular}

whey protein concentrate. Product response values resulted in identification of a combination that satisfied the constraints. Finally the Pasta was prepared using the recommended level of ingredients. The developed pasta was analyzed for its nutritional values and it was found that developed pasta (per 100g) contains protein $(10.16 \mathrm{~g})$, fat $(6.0 \mathrm{~g})$, dietary-fiber $(16.71 \mathrm{~g})$, calcium $(4.23 \mathrm{mg})$, iron $(3.99 \mathrm{mg})$ and zinc $(1.682 \mathrm{mg})$.

\section{Conclusions}

Product responses lightness, firmness, gruel loss and overall acceptability of the prepared pasta were affected by ingredients FMF, PMF and CMC. The present study showed that pasta with good nutritional and functional properties can be obtained from blends by incorporating 20gFMF, 12gPMF, 4gCMC $100 \mathrm{~g}^{-1} \mathrm{CF}$ with OAA (8.1). The pasta prepared from the composite flours contained higher levels of protein, dietary fiber, calcium, iron and zinc and may offer the inherent health benefits of millets especially phytochemicals to the consumer. Moreover the results of this study could provide the industry useful information about potential utilization of millet grains in food formulations and product development for new functional foods.

\section{Acknowledgements}

The first author thanks UGC New Delhi for the grant of (MANF) junior research fellowship to carry out this research work.

\section{References}

Alamprese, C., Casiraghi, E., \& Pagani, M. A. (2007). Development of gluten free fresh egg pasta analogues containing buckwheat. European Food Research, 225(2), 205-213. http://dx.doi.org/10.1007/ s00217-006-0405-y.

American Association of Cereal Chemists - AACC. (2000). Approved methods of the AACC (10th ed.). St. Paul.

Brennan, C. S., \& Tudorica, C. M. (2007). Fresh pasta quality as affected by enrichment of nonstarch polysaccharides. Journal of Food Science, 72(9), S659-S665. http://dx.doi.org/10.1111/j.17503841.2007.00541.x. PMid:18034751.

Bub, A., Watzl, B., Abrahamse, L., Delincée, H., Adam, S., Wever, J., Müller, H., \& Rechkemmer, G. (2000). Moderate intervention with carotenoid-rich vegetable products reduces lipid peroxidation in men. The Journal of Nutrition, 130(9), 2200-2206. PMid:10958813.

Caperuto, L., Amaya-Farfan, J., \& Camargo, C. R. O. (2001). Performance of quinoa (Chenopodium quinoa Willd) flour in the manufacture of gluten-free spaghetti. Journal of the Science of Food and Agriculture, 81(1), 95-101. http://dx.doi.org/10.1002/10970010(20010101)81:1<95::AID-JSFA786>3.0.CO;2-T.

Chillo, S., Laverse, J., Falcone, P. M., \& Del Nobile, M. A. (2007). Effect of carboxy methyl cellulose and pregelatinized corn starch on the quality of amaranthus spaghetti. Journal of Food Engineering, 83(4), 492-500. http://dx.doi.org/10.1016/j.jfoodeng.2007.03.037.

Chillo, S., Laverse, J., Falcone, P. M., \& Del Nobile, M. A. (2008). Quality of spaghetti in base amaranthus wholemeal flour added with quinoa, broad bean and chick pea. Journal of Food Engineering, 84(1), 101107. http://dx.doi.org/10.1016/j.jfoodeng.2007.04.022.

Fernandes, M. D. S., Sehn, G. A. R., Leoro, M. G. V., Chang, Y. K., \& Steel, C. J. (2013). Effect of adding unconventional raw materials on the technological properties of rice fresh pasta. Food Science and Technology, 33(2), 257-264.

Gallagher, E., Gormley, T. R., \& Arendt, E. K. (2004). Recent advances in the formulation of gluten-free cereal-based products. Trends in Food Science \& Technology, 15(3-4), 143-152. http://dx.doi.org/10.1016/j. tifs.2003.09.012.

Gull, A., Prasad, K., \& Kumar, P. (2015). Effect of millet flours and carrot pomace on cooking qualities, color and texture of developed pasta. LWT Food Science and Technology, 63(1), 470-474. http:// dx.doi.org/10.1016/j.lwt.2015.03.008.

Juszczak, L., Witczak, T., Ziobro, R., Korus, J., Cieślik, E., \& Witczak, M. (2012). Effect of inulin on rheological and thermal properties of gluten-free dough. Carbohydrate Polymers, 90(1), 353-360. http:// dx.doi.org/10.1016/j.carbpol.2012.04.071. PMid:24751052.

Kaur, G., Sharma, S., Nagi, H. P. S., \& Dar, B. N. (2012). Functional properties of pasta enriched with variable cereal brans. Journal of Food Science and Technology, 49(4), 467-474. http://dx.doi.org/10.1007/ s13197-011-0294-3. PMid:23904655.

Krishnan, M., \& Prabhasankar, P. (2010). Effect of pasting, microstructure, sensory and nutritional profile of pasta influenced by sprouted finger millet (Eleucina Coracana) and green banana (Musa Paradisiaca) flours. Journal of Texture Studies, 41(6), 825-841. http://dx.doi. org/10.1111/j.1745-4603.2010.00257.x.

McDonough, C. M., \& Rooney, L. W. (1989). Structural characteristics of Pennisetum americanum (pearl millet) using scanning electron and florescence microscopy. Food Microstructure, 81, 137-149.

Noni, I., \& Pagani, M. A. (2010). Cooking properties and heat damage of dried pasta as influenced by raw material characteristics and processing conditions. Critical Reviews in Food Science and Nutrition, 50(5), 465-472. http://dx.doi.org/10.1080/10408390802437154. PMid:20373190.

Obilana, A. B., \& Manyasa, E. (2002). Millets. In P. S. Belton \& J. R. N. Taylor (Eds.), Pseudocereals and less common cereals (pp. 177-214). Berlin: Springer. http://dx.doi.org/10.1007/978-3-662-09544-7_6. 
Prabhasankar, P., Ganesan, P., Bhaskar, N., Hirose, A., Stephen, N., Gowda, L. R., Hosokawa, M., \& Miyashita, K. (2009). Edible Japanese seaweed, wakame (Undaria pinnatifida) as an ingredient in pasta: chemical, functional and structural evaluation. Food Chemistry, 115(2), 501-508. http://dx.doi.org/10.1016/j.foodchem.2008.12.047.

Raina, C. S., Singh, S., Bawa, S., \& Saxena, D. C. (2005). Textural characteristics of pasta made from rice flour supplemented with proteins and hydrocolloids. Journal of Texture Studies, 36(4), 402420. http://dx.doi.org/10.1111/j.1745-4603.2005.00024.x.

Ranganna, S. (1986). Handbook of analysis and quality control for fruits and vegetable products (chapt. 1, pp. 1-30). New Delhi: Tata McGraw-Hill.

Rathi, A., Kawatra, A., \& Sehgal, S. (2004). Influence of de-pigmentation of pearl millet (Pennisetum glaucum) on sensory attributes, nutrient composition, in vitro protein and starch digestibility of pasta. Food Chemistry, 85(2), 275-280. http://dx.doi.org/10.1016/j. foodchem.2003.06.021.

Saravana, M., \& Soam, S. K. (2010). Exploitation of minor millets genetic resources for poverty alleviation in India. In National Conference on Biodiversity, Development and Poverty Alleviation, Lucknow, India.

Schoenlechner, R., Mandala, I., Kiskini, A., Kostaropoulos, A., \& Berghofer, E. (2010). Effect of water, albumen and fat on the quality of gluten-free bread containing amaranth. International Journal of Food Science \& Technology, 45(4), 661-669. http://dx.doi. org/10.1111/j.1365-2621.2009.02154.x.
Sharma, K. D., Karki, S., Thakur, N. S., \& Attri, S. (2012). Chemical composition, functional properties and processing of carrot-a review. Journal of Food Science and Technology, 49(1), 22-32. http://dx.doi. org/10.1007/s13197-011-0310-7. PMid:23572822.

Shiau, S. Y. (2004). Effect of emulsifiers on dough rheology properties and the texture of extruded noodles. Journal of Texture Studies, 35(1), 93-110. http://dx.doi.org/10.1111/j.1745-4603.2004.tb00824.x.

Sudha, M. L., \& Leelavathi, K. (2012). Effect of blends of dehydrated green pea flour and amaranth seed flour on the rheological, microstructure and pasta making quality. Journal of Food Science and Technology, 49(6), 713-720. http://dx.doi.org/10.1007/s13197010-0213-z. PMid:24293690.

Vidyavati, H. G., Begum, M. G., Vijayakumar, J., Gokavi, S. S., \& Begum, S. (2004). Utilization of finger millet in preparation of Papad. Journal of Food Science and Technology, 41(4), 379-382.

Yadav, D. N., Balasubramanian, S., Kaur, J., Anand, T., \& Singh, A. K. (2014). Non-wheat pasta based on pearl millet flour containing barley and whey protein concentrate. Journal of Food Science and Technology, 51(10), 2592-2599. http://dx.doi.org/10.1007/s13197012-0772-2. PMid:25328200.

Yalcin, S., \& Basman, A. (2008). Effects of gelatinization level, gum and transglutaminase on the quality characteristics of rice noodle. International Journal of Food Science \& Technology, 43(9), 1637-1644. http://dx.doi.org/10.1111/j.1365-2621.2007.01674.x. 